\title{
INCIDENCE OF AIRBORNE FUNGI IN RAJSHAHI METROPOLITAN CITY IN RELATIONTO SEASONAL FLUCTUATIONS
}

\author{
Most. Ferdousi Begum*, Shahidul Alam and Md. Shah Alam \\ Department of Botany, University of Rajshahi, Rajshahi-6205
}

\begin{abstract}
Using PDA, Saboraud's, Czapek's and Richard's media and settling plate technique, a total of 16, 593 fungal colonies belonging to 28 genera were identified during November 2006 and October 2007 in the atmosphere of the Rajshahi Metropolitan City. Seasonal fluctuations in the incidence of airborne fungi and their relation to some meteorological parameters were noticed. The incidence varied significantly by seasons. Maximum incidence of air borne fungi was recorded from November to January, where as the minimum was found from August to October. The most prevalent fungal genera were Aspergillus, Candida, Penicillium, Rhizopus, Fusarium, Alternaria, Curvularia and Cladosporium in respect of seasons. Aspergillus was the most dominting fungi contributed 25.6, 26.3, 24.4 and 26.3\% in PDA, Sabouraud's, Czapek's and Richard's media, respectively during the twelve months of observation. The percentage contributions of the most predominant 14 genera were 83.1, 84.1, 83.9 and 885.6 collected in PDA, Sabouraud's, Czapek's and Richard's media, respectively. Rest of the 14 genera were covering about 8.3, 8.0, 7.1 and $84.2 \%$ of the total aero-fungi and sterile mycelium and unidentified fungi were contributed 7.8, 7.4, 8.4 and $8.1 \%$, respectively.
\end{abstract}

Key words: Airborne fungi, incidence, culture media, season, fluctuation.

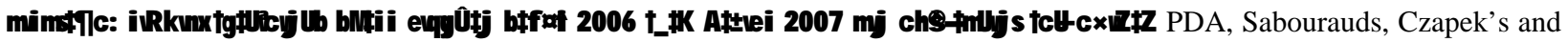

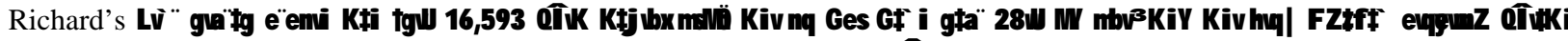

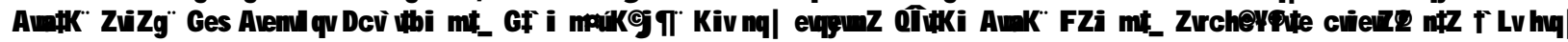

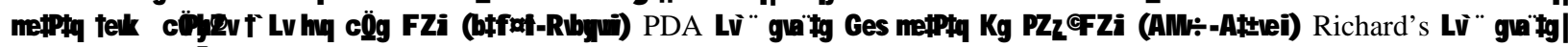
mełPła c ÖbOK@QI K MY nłj v Aspergillus, Candida, Panicillium, Rhizopus, Fusarium, Alternaria, Curvularia and Cladosporium hv

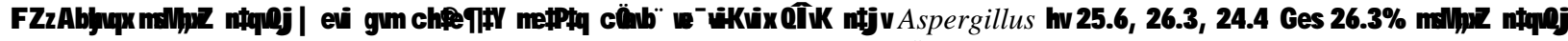

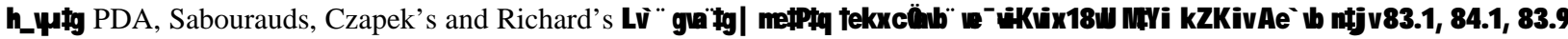

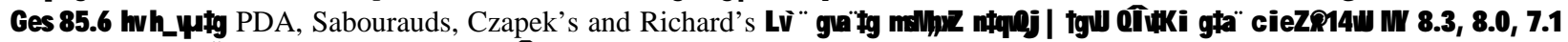

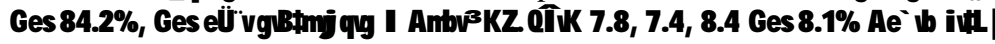

\section{Introduction}

Airborne microbe is a component of our environment and is of potential economic and health implications (Gregory, 1961; Hashimoto, 1986). There are essentially no fungus-free environments in our daily lives (Chao et al., 2002). Moreover, viable microbes in extramural air may be responsible for many illness during certain seasons of the year and may have serious consequence (Cantane et al., 1984; Maestreet et al., 1986). Exposure to fungi has been reported to cause several types of human health problems, primarily irritations, infections, allergies, and toxic effects, and it has been suggested that toxigenic fungi are the cause of additional adverse health effects (Etzel et al., 1994; Hodgson et al., 1998; Epstein and Fan, 2001). A field guide published by the American Industrial Hygiene Association recommends that the presence of some toxigenic fungi requires urgent risk management decisions (Dillon et al., 1996). To systematically evaluate the relationship between airborne fungi and adverse health effects, the fungal types and their relative frequencies in air need to be known (Shelton et al., 2002).

*Corresponding author
Air is the most common medium for the dispersal of fungal spores and hyphal fragments (Marchisio et al., 1992). The composition and concentrations of the airborne fungal spores are largely determined by geographic location, meteorological factors, vegetation, and human activities (Lacey, 1981; Lyon et al., 1984). The concentrations of fungal spores in the atmosphere at any particular moment are influenced by the processes involved in their production, release, and deposition (Lyon et al., 1984). The influence of meteorological factors on the concentrations of airborne spores appears to be additive, not independent (Munk, 1981). Keeping the above views in mind, the present investigation was undertaken to study the incidence of atmospheric fungi in the Rajshahi Metropolitan City and to find out the possible relations between the obtained data and the prevailing climatic conditions. The incidence of airborne fungi and their fluctuations by seasons were also recorded.

\section{Materials and Methods}

Sample site: The sampling was conducted in outdoor atmosphere at different places of Rajshahi Metropolitan 
City, especially Rajshahi University Campus and satellite town (Upashahar) areas from November 2006 to October 2007.

Sample collection: The air samples were collected per week followed by settling plate culture method (Brown, 1953) using Potato Dextrose Agar (PDA), Richard's, Czapek's and Saboraud's media. To avoid bacterial contamination, 50\% lactic acid was added to the media. The Petri dishes (9 cm-diameters) containing $20 \mathrm{ml}$ selected media were exposed at $1 \mathrm{~m}$ height from ground level in every cases for $15 \mathrm{~min}$. Then the plates were taken into the laboratory and incubated at $30^{\circ} \mathrm{C}$ for 5-7 days. Meteorological data were collected from Government Meteorological Information Centre, Rajshahi.

Microbial examination: The fungal colonies were enumerated after their growth on the plates. Identification of fungal colonies was made by visual and microscopic examinations. Identification up to generic level was done with the help of standard mycological books and manuals (Gilman, 1957; Booth, 1971; Subramanian, 1971; Ellis, 1971; Alexopoulos and Mims, 1979). Sub-cultures that failed to sporulate at the end of one month was designated as sterile mycelium. Details regarding the qualitative nature of the mycoflora, their incidence, abundance and percentage contribution were recorded. The percentage contribution of each genus was calculated on the basis of the number of colonies of the genus against total number of colonies of all recorded genera during the entire twelve months' sampling period. Seasonal variations in fungi were also carried out.

Statistical analyses: The experiment was conducted by using a randomised design with five replications. Using a statistical package (MSTAT-C) all data were analysed by F-tests (analysis of variance) and the comparison of means were done separately. Correlation was determined among the season and different fungi. Results of all analyses were judged for their significance at $5 \%$ level.

\section{Results and Discussion}

A total of 16,593 colonies were recorded in PDA, Sabouraud's, Czapek's and Richard's media. Out of these 15,279 colonies were identified, 1,171 were sterile mycelium and 143 were unidentified. The isolated fungi were assigned to 28 genera belonging to Phycomycetes, Ascomycetes, Basidiomycetes and Deuteromycetes. The range of temperature, average $\mathrm{RH}$ (relative humidity) and rainfall were gathered from Meteorological Information Centre (Table 1). Among the four media tested, PDA was the most favourable for growth and development of identified fungi and showed the highest count. The data showed clear variations on different climatic factors in different seasons (Table 1). The prevalence of airborne mycoflora was intimately related with prevalent climatic conditions including temperature and RH (Wright et al., 1969; Webb, 1959).

Season-wise fluctuations in the incidence of airborne fungi: Seasonal counts of fungal colonies in four culture media were determined. Total number of fungal colonies were counted as 1566, 1440, 1171 and 1091 in $1^{\text {st }}$ season ; 969, 1045,956 , and 849 in $2^{\text {nd }}$ season ; 1054, 1034, 960 and 869 in $3^{\text {rd }}$ season ; and 1073, 1002, 735 and 700 in $4^{\text {th }}$ season in PDA, Sabouraud's, Czapek's and Richard's media, respectively. Statistical analysis revealed that positive and significant correlation $(\mathrm{r}=0.767 ; \mathrm{P}<0.05)$ was present in different seasons and colony number of different fungi. Analysis of variance showed significant $\left(\mathrm{F}_{3,89}=3.977 ; \mathrm{P}<0.05\right)$ results in different seasons and in different fungi.

The incidence of airborne fungi varied from season to season. The maximum incidence of air borne fungi were exhibited in the atmosphere of the $1^{\text {st }}$ season(November to January) in PDA medium and the minimum in $4^{\text {th }}$ season (August to October) in Richard's medium. Chao et al. (2002) reported that total airborne fungal concentrations varied significantly by season and noted highest in summer and lowest in winter. Shelton et al. (2002) observed the highest fungal population in the fall and summer and lowest in the winter and spring. Uddin (2005) reported that temperature and relative humidity is probably not so significant for aeromycoflora of jute fields but the incidence of aeromycoflora is inversely proportional to the total rainfall. Chakraborty et al. (2003) reported that there were no significant correlation between total air spora and the meteorological parameters and local cropping practices may have some regulating role on spore concentration in the air.

Season-wise airborne fungal genera: The genera Aspergillus, Candida, Penicillium, Rhizopus, Fusarium, Alternaria, Curvularia and Cladosporium were the most frequently occurring fungi in all the seasons as recorded in PDA, Sabouraud's, Czapek's and Richard's media. Among the genera, Aspergillus was the most predominant and showed highest incidence in $3^{\text {rd }}$ and $4^{\text {th }}$ seasons (May to October) in PDA medium where high temperature and heavy rainfall were recorded (Table 1). Candida is the $2^{\text {nd }}$ dominating fungi and showed the highest incidence in $1^{\text {st }}$ season (November to January) in PDA medium where low temperature and minimum 
rainfall were recorded. The $3^{\text {rd }}$ dominating fungi was Penicillium sp. showed the highest incidence in $3^{\text {rd }}$ season (May to July) in Czapek's medium whereas Rhizopus and Colletotrichum showed maximum incidence in $2^{\text {nd }}$ season (February to April). The highest incidence of common fungi as Fusarium, Alternaria, Curvularia, Cladosporium, Monilia, Helminthosporium, Geotrichum, Trichoderma and Gleocladiopsis were recorded in $1^{\text {st }}$ season whereas Oidiodendron was recorded maximun in $3^{\text {rd }}$ season and Mucor in $2^{\text {nd }}$ season. Maximum sterile mycelium were exhibited in $3^{\text {rd }}$ and $4^{\text {th }}$ seasons (May to October) of the total count as recorded in PDA, Sabouraud's, Richard's and Czapeks media (Table 2). Begum et al. (2007) reported that Penicillium, Sporobolomyces, Aspergillus, Neurospora, Cladosporium, Alternaria, Curvularia, Fusarium, Gloeosporium and Candida were the most frequent genera of Rajshahi Metrpolitan City. Uddin (2005) reported that Penicillium and Aspergillus are the most dominant fungi followed by Curvularia and Cladosporium. Chakraborty et al. (2003) studied aeromycoflora in an agricultural farm at a suburban area of Calcutta and reported that the most abundant types were basidiospores (21.85\%) followed by Cladosporium, Penicillium, Nigrospora, Aspergillus and ascospore. Albuquerque et al. (2004) studied airborne fungi of Brazil and reported that Aspergillus, Penicillium, Curvularia, Cladosporium, mycelial sterila, Fusarium, Rhizopus, Dreschleria, Alternaria, and Absidia were predominant fungi. Shelton et al. (2002) stated that Cladosporium, Penicillium and non sporulating fungi are prevelance fungi in the air of U.S.A. Maestre et al. (1986) observed that frequently isolated air borne fungi were Aspergillus followed by Penicillium, Candida, Alternaria, Cephalosporium and Rhizopus. Paramasivam and Gnanarethinum (1986) noted that Aspergillus, Penicillium, Cladosporium and Drechslera were frequent genera contributed $80 \%$ of the sporal load. The present results support the above findings.

Percentage contribution of airborne fungi: Among all the identified genera the highest percentage covering genus is Aspergillus contributed 25.6, 26.3, 24.4 and 26.3\% in PDA, Saborauds, Czapek's and Richard's media recorded as total colony number 4261 in different seasons and in different media. The next dominant genus was recorded in this investigation is Candida and contributed about 20.6, 23.8, 26.7 and $26.6 \%$ of the total counts as in PDA, Sabourauds, Czapeck's and Richards media showing colony number 4009 in different seasons and in different media. In order of rank third position is Penicilllium contributed 7.0, 8.5, 11.7 and $11.8 \%$ of the total count as in PDA, Sabourauds, Czapek's and Richard's media in different seasons and different media. Next in order is Rhizopus. constituting flora in November, 2001 to October, 2002 and contributed $6.4 \%, 4.2 \%, 1.7 \%$ and $2.9 \%$ in PDA, Sabouraud's, Czapek's and Richards's media, respectively. Fusarium, Alterneria, Curvularia, Cladosporium, Monilia and Helminthosporium belongs to the following status covering 3.8, 2.6, 3.7, 2.8, 3.0 and $2.6 \%$ in PDA ; 6.2, 3.5, 2.7, 2.6, 0.8 and 2.8\% in Sabouraud's; 1.7,3.9,1.7, 5.2,2.2 and 0.8 \% in Czapek's and 3.4, 2.4, 2.5, 2.5, 1.1 and 1.5\% in Richard's medium among the total air borne fungi. Papularia contributed $2.4 \%$ of the aeromycoflora in PDA. The next of 16 genera viz. Geotrichum, Colletotrichum, Trichoderma, Oidiodendron, Gleocladiopsis, Mucor, Epicoccum, Botrytis, Cephalosporium, Leptographium, Gleocladium, Pullularia, Wardomyces, Fusaiella, Streptomyces, Xylohypha and Trichophyton had a little contribution. Sterile mycellium were contributed 7.0, 6.7, 7.2 and $7.2 \%$ and unidentified fungi were $0.8,0.7,1.2$ and $0.9 \%$ of the total count of aerofungi as recorded in PDA, Sabouraud's, Czapek's and Richard's media, respectively. The variations among the most five dominant air borne fungi are shown in Fig. 1 to 4.

The prevalence of atmospheric fungi: Prevalence of 14 genera viz. Aspergillus, Candida, Penicillium, Rhizopus, Fusarium, Alternaria Carvularia, Cladosporium, Monilia, Helmonthosporium, Papularia, Geotrichum, Colletotrichum and Trichoderma were recorded 83.1, 84.1, 83.9 and 885.6\% in PDA, Sabouraud's, Czapek's and Rhichard's media, respectively during total twelve months observation from November, 2006 to October, 2007 (Fig. 5). Rest of the 14 genera were recorded 8.3, 8.0, 7.1 and $84.2 \%$ in the above mentioned media, respectively. Sterile mycelium and unidentified fungi were recorded as 7.8, 7.4, 8.4 and 8.1\%, respectively.

The relationships between climate and fungi are complex, and should be examined from numerous perspectives (Sneller, 1984). The effect of the meteorological factors varied among seasons ( $\mathrm{Li}$ and Kendrick, 1995). Many environmental factors are interrelated and it is often difficult to know which the most significant (Skre, 1981). The averages of the meteorological factors are generally more important than maximum and minimum values ( $\mathrm{Li}$ and Kendrick, 1995). A better understanding of the relative importance of these factors and their relationships would be of help in determining the relationships of air borne spores to allergies caused by airborne fungal spores (Lyon et al., 1984). 
Table 1. Monthly variations in total fungal colony counts with respect to temperature, average relative humidity and rainfall

\begin{tabular}{|c|c|c|c|c|c|c|c|c|c|}
\hline \multirow[b]{2}{*}{ Months } & \multicolumn{3}{|c|}{ Temperature $\left({ }^{\circ} \mathrm{C}\right)$} & \multirow{2}{*}{$\begin{array}{c}\text { Average relative } \\
\text { humidity (\%) }\end{array}$} & \multirow{2}{*}{$\begin{array}{c}\text { Rainfall } \\
\text { (mm) }\end{array}$} & \multicolumn{4}{|c|}{ Total colonies on } \\
\hline & Maximum & Minimum & Mean & & & $\begin{array}{c}\text { PDA } \\
\text { medium }\end{array}$ & $\begin{array}{l}\text { Sabouraud's } \\
\text { medium }\end{array}$ & $\begin{array}{l}\text { Czapek’s } \\
\text { medium }\end{array}$ & $\begin{array}{c}\text { Richard's } \\
\text { medium }\end{array}$ \\
\hline November & 28.7 & 17.8 & 24.2 & 81 & 10.8 & 446 & 500 & 276 & 358 \\
\hline December & 26.3 & 12.6 & 19.4 & 79 & 0 & 472 & 445 & 428 & 392 \\
\hline January & 24.5 & 9.4 & 16.9 & 76 & 0 & 645 & 495 & 467 & 352 \\
\hline February & 26.4 & 14.6 & 20.5 & 79 & 26.4 & 303 & 296 & 351 & 325 \\
\hline March & 31.1 & 17.1 & 24.1 & 67 & 28.8 & 361 & 379 & 344 & 202 \\
\hline April & 35.4 & 23.7 & 29.5 & 69 & 13.8 & 305 & 270 & 261 & 318 \\
\hline May & 36.1 & 24.9 & 30.5 & 75 & 125.8 & 349 & 275 & 336 & 321 \\
\hline June & 33.8 & 25.6 & 29.7 & 84 & 312.1 & 397 & 363 & 355 & 263 \\
\hline July & 31.5 & 26.6 & 29.0 & 88 & 362.4 & 311 & 396 & 275 & 283 \\
\hline August & 33.2 & 26.6 & 29.9 & 86 & 235.7 & 315 & 318 & 190 & 188 \\
\hline September & 32.8 & 26.1 & 29.4 & 87 & 306.9 & 366 & 302 & 248 & 196 \\
\hline October & 31.9 & 23.3 & 27.6 & 85 & 75.4 & 386 & 382 & 297 & 316 \\
\hline
\end{tabular}

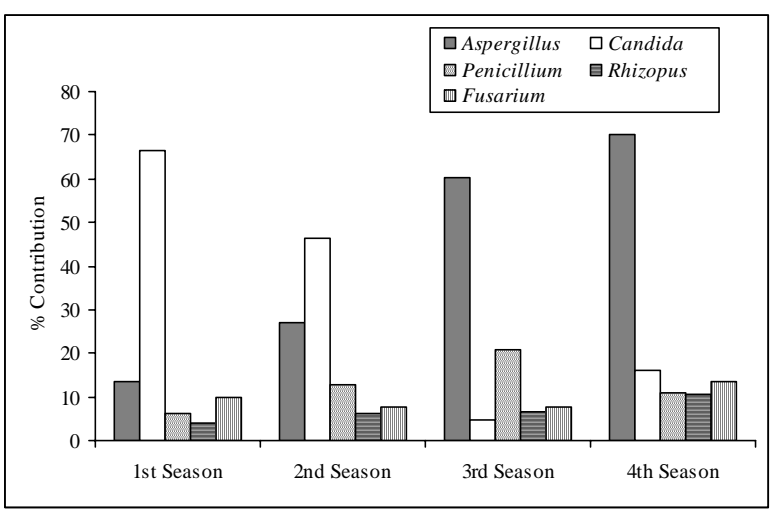

Fig. 1. Percentage contribution of five dominant airborne fungi trapped in the air of Rajshahi Mertropolitan City in different seasons in PDA medium.

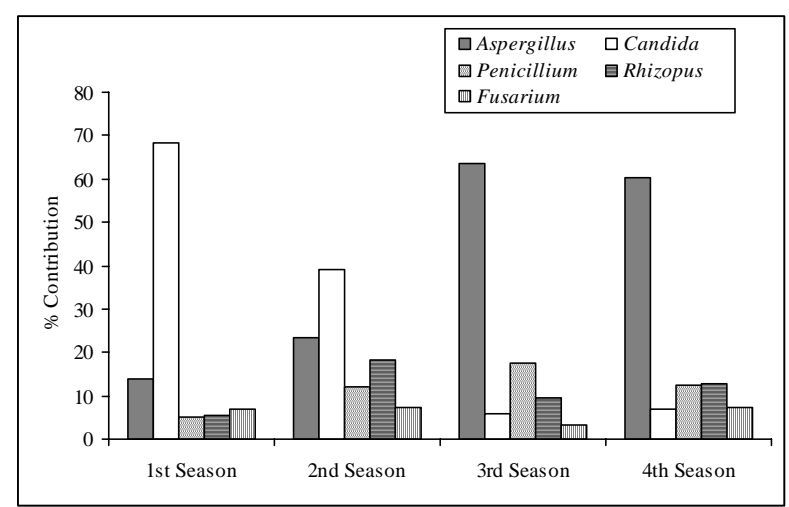

Fig. 2. Percentage contribution of five dominant airborne fungi trapped in the air of Rajshahi Mertropolitan City in different seasons in Saboraud's medium.

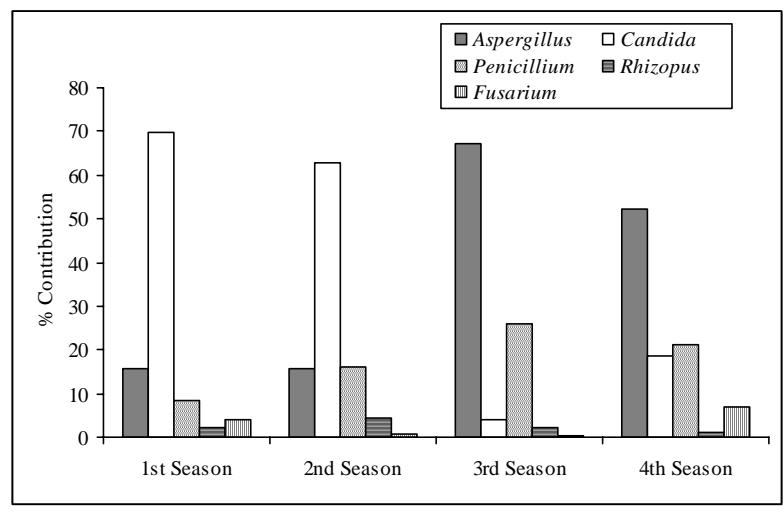

Fig. 3. Percentage contribution of five dominant airborne fungi trapped in the air of Rajshahi Mertropolitan City in different seasons in Czapek's medium.

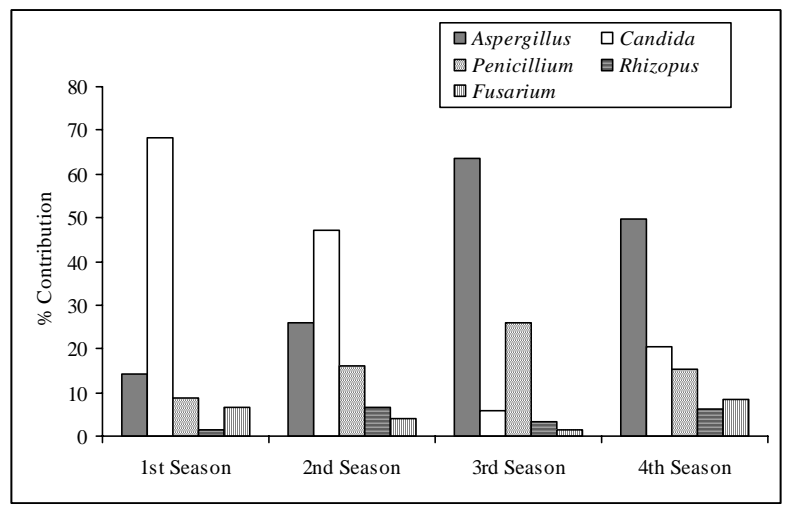

Fig. 4. Percentage contribution of five dominant airborne fungi trapped in the air of Rajshahi Mertropolitan City in different seasons in Richard's medium. 


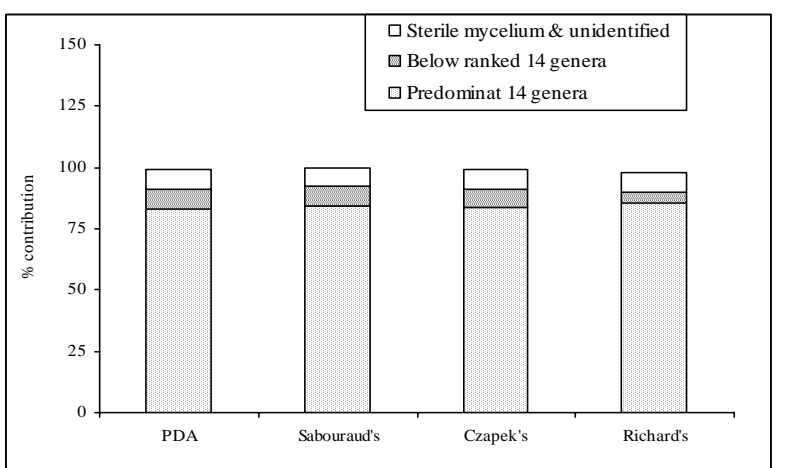

Fig. 5. Prevalence of airborne fungi in the air of Rajshahi Metropolitan City in different media from November 2006 to October 2007.

\section{Conclusion}

Climate plays important role in the initiation and exacerbation of mould induced allergic symptoms in man. In order to understand fully the influences of airborne fungi on human allergies, indoor studies should be carried out in parallel to out door studies for distinguishing their roles in triggering allergies. The present work provides important information on airborne fungal incidence in outdoor environment, which is helpful in making public awareness as well as successful hygienic sanitation programmes.

\section{References}

Albuquerque EM, Percira CET, Marcia MC, Fertado CCF. 2004. Airborne fungi isolated from Fortaleza City, State of Ceara, Brazil. Revizta Inst. Med. Tvop. Sao Paulo. May/June.

Alexopoulos CJ, Mims CW. 1979. Introductory Mycology ( $3^{\text {rd }}$ edn.). John Wiley and Sons. Inc., U.S.A.

Begum MF, Begum F, Alam S, Alam MS. 2007. Frequency and distribution of air borne fungi in urban and peri-urban areas of Rajshahi City. Plant Environ. Dev. 1(1): 29-36.

Booth C. 1971. The Genus Fusarium. Commonwealth Mycological Institute. Kew, Surrey, England.

Chakraborty PS, Bhattacharya G, Chanda S. 2003. Aeromycoflora of an agricultural firm in west Bengal India.: A five years study (1994-1999). Grana 42(4): 248-254.

Chao HJ, Schwartz J, Milton DK, Burge HA. 2002. Populations and determinants of airborne fungi in large office buildings. Environ. Health Perspective 110(8): 118- 130 .

Contane NF, Smith DT, Baker RD, Callaway JL Martin DS. 1984. Manual of Clinical Mycolgy ( $2^{\text {nd }}$ edn). Saunders, Philadelphia.

Dillon HK, Heinsohn PA, Iller J. 1996. Field guide for the determination of biological contaminants in environmental samples. pp 24-58. American Industrial Hygiene Association, Fairfax, VA.

Ellis MB. 1971. Dematiatiaceous Hypomycetes. Commonwealth Mycological Institutes. Kew, Surrey, England.
Epstein CE, Fan LL. 2001. Alveolar haemorrhage syndromes: update on pulmonary haemosiderosis. J. Respir. Dis. Pediatr. 3: 49-56.

Etzel RA, Montana E, Sorenson WG, Kullman GJ, Allan TA, Dearborne DG. 1994. Acute Pulmonary haemorrhage in infants associated with exposure to Stachybotrys atra and other fungi. Arch. Pediatr. Adolesc. Med. 152: 757-762.

Gilman JC. 1957. A manual of Soil Fungi. Iowa State Univ. Press.

Gregory PH. 1961. The Microbiology of Atmosphere. Inter Science Publishers. New York.

Hashimoto S. 1986. Study on airborne fungal flora. The distribution of airborne fungi in the homes of children with bronchial asthma. J. Tokyo Womens Med. Col. 56(10/1): 969-980.

Hodgson MJ, More P, Leung WY, Morrow L, Miller D, Jervis BB, Robbins H, Halsey JF, Storey E. 1998. Buildingassociated pulmonary disease from exposure to Stachybotrys chartarum and Aspergillus versicolour. J. Occup. Environ. Med. 40: 241-249.

Lacy J. 1981. The aerobiology of conidial fungi. In: Biology of Conidial Fungi, eds. Cole G.T. Kendrick B (Vol. 1), pp 373-415, Academic Press. New York.

Li D-W, Kendrick B. 1995. A year-round study on functional relationships of airborne fungi with meteorological factors. Int. J. Biometeorol. 39: 74-80.

Lyon FL, Framer CL, Eversmeyer MG. 1984. Variation of airspora in the atmosphere due to weather conditions. Grana 23: 177-181.

Maestre JR, Picazo JJ, Fereres J, Jurrado LAL, Balaneooria M. 1986. Airborne fungal spores as a risk factor in the hospital environment. Infectologia 7(3): 27-28.

Marchisio VF, Nosenzo C, Caramiello. R. 1992. Preliminary survey of airborne fungal propoagules in Turin, Italy. Mycol. Res. 96: 535-541.

Munk L. 1981. Dispersal of Erysiphae graminuis conidia from winter barley. Grana 20: 215-217.

Paramasivum M, Gnanarethinum JL. 1986. A preliminary survey of the atmospheric fungal flora of Tiruchira Pali India. J. Microbiol. 26(1\&2): 117-119.

Shelton GB, Kirkland HK, Flanders WD, George KM. 2002. Profiles of airborne fungi in building and outdoor environments in the United States. Appl. Env. Microbiol. 68(4): 1743-1753.

Skre O. 1981. The amounts and properties of transported air at two Norwegian stations as functions of wind direction and weather type. Grana 20: 169-178.

Sneller MR. 1984. Mould allergy and climate conditions. In: Mould allergy. eds Al-Doory Y., Domson JF, pp. 244266. Lea and Febiger, Philadelphia.

Subramanian CV. 1971. Hypomycetes. Indian Council of Agricultural Research, New Delhi, India.

Uddin, N. 2005. Estimation of aeromycoflora in jute fields. Aerobiologia 21(1): 70-80.

Webb SJ. 1959. Factors affecting the viability of airborne bacteria. Canadian J. Microbiol. 5: 649.

Wright J, Greene JVW, Panlas HJ. 1969. Viable microorganisms in an urban atmosphere. Air Poll. Control Assoc. 19: 337-339. 